\title{
Deployment of Information Communication Technology for Teaching and Learning Engineering Technological Skills: A Case of National Polytechnics in Kenya
}

\author{
Mutai Cheruiyot Daniel
}

\section{ABSTRACT}

The knowledge economy expansion has significantly affected the methodologies of knowledge transfer and skilling of human resource. The demand for skillful workforce is significant to the development of an ingenious educational approach to teaching and learning engineering. Integration of Information Communication Technology (ICT) in teaching and learning provides a number of endless interactive modernizations of training approaches to engineering processes and applications. The purpose of this study was to establish the status of integration of ICT in teaching and learning of practical engineering concepts in National Polytechnics in Kenya. The study surveyed the trainers' competencies on the application of ICT for the teaching and learning engineering processes and practices. The descriptive research design was employed and involved both quantitative and qualitative data. The study was based on the constructivist theory of learning and under the framework of technology, organization and environmental theory. Qualitative data was collected through Interviews and observation while questionnaires produced quantitative data. Three National polytechnics selected provided 63 respondents consisting of 48 trainers picked using stratified simple random sampling, while 12 administrators from mechanical, electrical, and automotive and civil engineering departments were selected by simple purposive sampling; to provide information on the trainers' competence on virtual teaching and learning engineering. The data was analyzed using descriptive statistics. The triangulation of the bidata collected through mixed method strengthened the overall outcome as one approach offset the weaknesses of the other method. The findings of the study identified the constraints getting in the way of trainers to effectively integrate ICT in teaching and learning engineering and the pointer centred on the inadequate knowledge on the application of simulations and unavailability of virtual laboratories; $64 \%$ of the engineering trainers reported that their computer proficiency was good while $36 \%$ reported to be moderately proficient in the use of computers. However, a depressed $17 \%$ had the capacity to employ simulation software for TL. The study recommended enhancement of trainers' competence on the application of ICT and provision of appropriate ICT infrastructure.

Keywords: virtual laboratory, engineering courses, ICT, teaching and learning, engineering technological skills.

\section{INTRODUCTION}

The Integration of ICT in teaching and learning is an innovative approach to the use of new technologies in equipping trainees with knowledge, skills and attitudes needed in many engineering fields. In Kenya globalization has left behind a huge population of graduates leaving training with enormous inferior skills creating skills gaps as the emerging technology has dictated development of new equipment for industry; calling for new up-and-coming skills.
Published Online: July 16, 2021

ISSN: $2736-4534$

DOI: $10.24018 /$ ejedu.2021.2.3.82

*Mutai Cheruiyot Daniel

Moi University, Eldoret, Kenya.

(e-mail: danmutai74@yahoo.com)

*Corresponding Author
According to Albirini [1] whereas, the use of ICT integration is to improve and increase the quality, accessibility and cost-efficiency of the delivery of instruction to trainees, it also connects the learning population to face the challenges brought about by globalization. This has widened the skills gap between the skill transfer in training institutions and the skills demand by the expanding digitalized industries. This has led to a mismatch between industry requirements and trainee skills.

The absorption of newly graduated trainees by industries has been reducing tremendously leading to unemployment or 
rather getting into an environment that is quite unfamiliar in terms of skills. This discrepancy in training has forced industry to retrain them or alternatively set up training department within the industry to train their own technicians. If Kenya is to achieve her Big four Agenda as visualized in Vision 2030 and Sustainable development goals, there is need to enhance quality engineering training.

Integration of ICT is the independent variable, whose effectiveness is influenced by three key variables namely trainer's knowledge and skills, attitudes and the availability of infrastructure. The target respondents were trainers' who are believed to be fully immersed in the framework of the institution operations set up and therefore greatly influenced the reliability of the findings of the study.

\section{E-LEARNING ENGINEERING TRAINING}

Integration of ICT in engineering training covers the use of ICT for delivery of classroom instructions on demonstration, conduct of laboratory experiments and class management. Classroom instructions are assisted by presentations that contain comprehensive course material, circuit, network and process diagrams, and flowcharts. In interrogating circuits, designs, models or processes simulation software compilers are used in instruction rooms for better understanding of the course content.

In demonstration of a working unit, operation of a circuit or functional processes, animations and visualizations are utilized. According to Banday et al [2] simulation software, engineering design and evaluation tools, intelligence planning tools such as MatLab, AutoCAD, Solid Works (3D) can be used in networked computing laboratory to demonstrate and conduct experiments which otherwise could have not been carried out in traditional workshops due to nonavailability of relevant or sufficient instruments or complexities of the process.

According to Gomes and García-Zubia [3] the engineering laboratory practices have not been an exception on the eLearning educational method. The evolving progress in technology over several years has allowed illustration of intricate configurations and objects by computer manipulations. The computers have also permitted course content to be digitized and learning engineering systems to be represented through simulation, animations, and videos. ICT integration in teaching and learning have provided an opportunity to set up virtual and remote laboratories to prop up life-long learning and autonomous trainee activities in several disciplines amongst them electronics and microelectronics, auto-science, control and automation, and drawing and designs.

Zhao and Frank [4] proposes that the process of technology integration enlarged as the teacher's beliefs, pedagogy, and technology skills slowly build upon each other as the technology is introduced and adapted into the institution's traditions. Abdellah and Taher [5] and Peterson [6] recognize ICT infrastructure as interactive media that creates a classroom environment that facilitates teaching and learning through internet connectivity or universal information access. The availability of ICT infrastructure influences the adoption and integration of ICT in teaching and learning. ICT provides teaching tools that are more effective in the learning process on the basis of virtual platform. According to UNESCO [7], virtual laboratories are defined as a workplace for remote collaboration and experimentation aimed at doing similar activities, reporting and disseminating the results. Virtual laboratories aid the trainees when they are carrying out practical activities and the use of computing software in teaching and learning allows the trainees to collaborate as knowledge is constructed. It also provides an opportunity to set up virtual laboratories to display the outcome of experiments and learn complex procedures.

The application of ICT is emerging as an essential element in this era of knowledge economy. Bryan and Slough [8] recognized Computer technology and its accessories as cognitive tools. Due to the fast expansion of Information and Communication Technologies, virtual laboratories are used as a substitute to the physical or real-life laboratories. Virtual laboratories have been developed in a number of engineering and scientific disciplines using a variety of simulation techniques and are based on simulation of real-life situations; providing an enabling environment for learners to construct knowledge that is transferable in practical situations. According to Alessi \& Trollip [9] computer simulation is a computer program that reproduces a real-life phenomenon, bringing the real world into classroom. The application of ICT in a cognitive-constructivist approach in teaching and learning is important to a more subjective, steadfast, and productive learning.

Banerji [10] observed that engineering training is very intricate; the knowledge to be acquired in this discipline is entirely far beyond records of information; technical knowledge is very dynamic. Trainees are liable to construct and reconstruct its meaning as they become familiar with conceptualization, analysis and maneuvering. Bailey \& Finkelstein [11] argued that workers who have worked with computer simulation learn more successfully. The virtual laboratories are more suited to handle a large number of trainees in that the cost to set-up, Operate and maintain a virtual laboratory is very low compared to a real laboratory. Setting up of virtual laboratory would be of great importance to TVET institution experiencing influx of trainees due to the current high demand for technical knowledge. Engineering virtual laboratories are being developed in many places around the world, involving virtual experiments in many fields such as Thermodynamics as utilized by Anderson [12], Computer Aided Design (CAD) by Jensen \& Raisor [13], Fluid-Mechanics by Higuchi [14], Circuit Design and many more. There are dedicated websites for engineering virtual laboratories in universities such as Purdue Engineering Laboratories at Purdue University.

\section{PROBLEM STATEMENT}

There is a mismatch between the skills acquired by the graduates of TVET institutions and the changing demand for new set of skills in the job market in both developed and developing countries. This may be attributed to the widening gap between the pace at which the formation of relevant human skills does not cope with the emerging technological and industrial processes. In a web-based tool used by Smaill [15] for skills practice and cumulative evaluation assisted trainers to manage workloads, while an electrical online 
laboratory designed by Zhai et al [16] enabled autonomous, interactive and collaborative learning of electrical engineering experiment.

The study carried out by Banday [17] identified several deficiencies in the conventional teaching and learning system followed for engineering education as inadequacy in traineetrainer interaction, complex teaching and learning and loss of synchronization amongst others. This skill mismatch has created a lot of concerns for Nations and Governments hence the need to address the challenge by use of e-learning; integration of information communication technology in teaching and learning to synchronize the human skill development and ever expanding emerging technological progression. This calls for re-alignment of training competencies with the advancement in industrial technology.

The emerging Information and Communication Technology provides an inducement for continuous learning and synchronization of skill development worldwide, in order to cope with the changing working environment. The Literature review has made it clear that computers have been used to impart technical skills to trainees. Computers are utilized pedagogically to simulate, or animate specific scientific operations aimed at enhancing understanding and insight of principles involved. The study sought to determine if TVET trainers in the field of engineering utilize ICT in teaching and learning technical skills and the level of virtual and remote laboratories establishment.

\section{RESEARCH OBJECTIVE}

The research objective was to describe the status of integration of ICT in teaching and learning and the trainers' competence in teaching and learning technical skills in engineering courses in National polytechnics.

\section{RESEARCH METHODOLOGY}

This study employed a Mixed Method Research design which is a combination of quantitative and qualitative research. This research design utilizes the two techniques and is advantageous in that it combines the strengths of the two approaches; providing a better and complete understanding of the research problem, reinforcing the focus and analysis of the trends and ensures that the study findings are factual experience and the understanding of the respondents befits this study. This is further supported by Johnson and Onwuegbuzie [18] and approved by Greene [19] that this approach presents researchers with opportunities to compensate for inbuilt methodology weaknesses and counteract unavoidable method predispositions and maximize on inherent method strengths. The research study embraced the descriptive survey research design

This study purposively sampled three (3) national polytechnics in Kenya on the basis of geographical location, status, and capacity in terms of enrolment, infrastructure and the years of existence. This is supported by Orodho and Kombo [20], that purposive sampling is the best in cases where the research purposely targets a cluster of respondents believed to be immersed and reliable in order to attain true representative sample of the study.
The target population consisted of 63 institutional administrators and trainers in Mechanical, Electrical and Electronic, Automotive and Civil Engineering departments. A sample of 48 trainers was selected by stratified and simple random sampling methods. 15 managers were selected through purposive sampling technique. The quantitative data was collected using questionnaires and qualitative by use of interviews and observation schedule. Descriptive and inferential statistics were used to analyze the quantitative data and the qualitative data after organization and theme categorization were analyzed using both narrative and discourse techniques; and finally, upshot was combined using triangulation to derive the conclusion.

\section{RESULTS AND DISCUSSION}

The findings and discussions of the study on utilization of ICT for teaching and learning technical skills in engineering courses in National Polytechnics in Kenya is presented in this section.

\section{A. Findings from Questionnaire}

The Multimedia group of skills are the abilities necessary for manipulating audio-visual objects using computer. The result in Chart 1 shows that $54 \%$ of the respondent reported to be skilled in using laboratory demonstration videos and animation. $56 \%$ of the respondents reported that they were skilled in using computer simulations. $40 \%$ of the respondents reported to be skilled in using Computer Aided design; Drafting software and others tools. 54\% of the respondents stated that they were skilled in using the digital images, while none had skills to use virtual tools. The findings also indicated that the trainers had never used the virtual instrument tools. The results generally indicated that half of the trainers have moderate skills in using multimedia.

The teaching and learning observed in the instruction rooms were either in the computer laboratories or demonstration rooms or in the smart classrooms. The equipment which was being used in this TL session was the basic media tools; computers, projectors and the smart boards and this accounted for $40 \%$. The technology which could play the role of connecting the learning concepts to real life situations; simulation software's and virtual tools were generally left at the side-line of teaching and learning. This agrees with the findings of Moeller and Reitze [21] that the trainers' use technology to present information rather than to provide hands on teaching and learning.

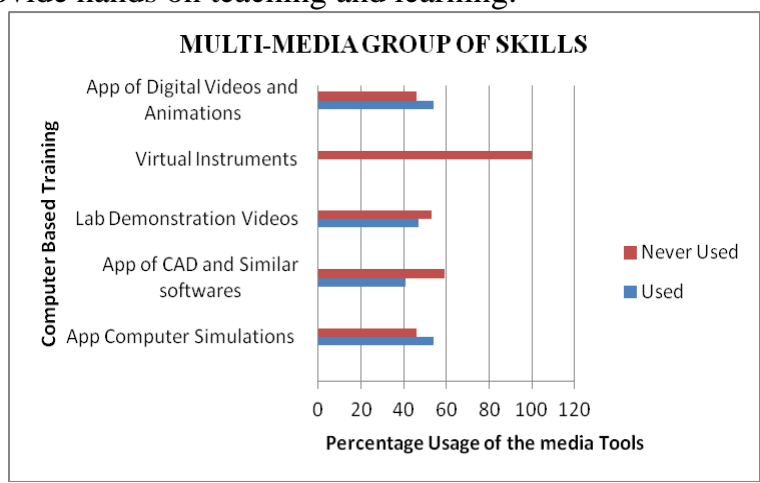

Fig. 1. Components of Computer Based Training. 


\section{B. Findings on the Interviews}

The administrators were asked about the main objective of setting up computer laboratories in their institutions. The response was captured as follows:

"The provision of computer laboratories were for purposes of training on the basic computer applications; carry out simple operations such as word processing techniques and simple elements of excel techniques.....the use of computers for content delivery in skill subject areas has not been part of the teaching and learning schedule or intention".

The application of the technology to support trainee centred learning has not been the focus of ICT integration in teaching and learning observes the administrators. The trainers were asked whether some of the ICT equipment the institutions had acquired were meant to enhance teaching and training. In the broad-spectrum the response was that every institution had received one or two smart boards for purposes showing some signs of technological development. However, the numbers were limited hence the facility was dedicated to few trainers who were enthusiastic and knowledgeable in computing. On the efficient and effectiveness on the use of smart classrooms installation, the administrators observed that:

"The Smart boards are special equipment for demonstration on the capacity of technology and its use for teaching was a reserve of a few; most valued and believed to be more knowledgeable, skillful in ICT and understand its manipulation for teaching and learning....the successive influence is so limited as the infrastructure and the enabling environment could not permit".

In order to effectively integrate ICT in instruction rooms, the trainers must be knowledgeable and skillful in the technology. In line with this Cavas et al [22] noted that there is close connection between the trainers' ICT skills and the frequency use of technology in the instruction rooms. Agyei and Voogt [23] confirmed that ICT skills are the strongest forward planner of ICT integration in instruction rooms. There is therefore needed to equip the agents of change; trainers with skills on the application of ICT technology in teaching and learning so as to carry out practical activities in virtual laboratories. During the interviews carried out among the head of engineering department there was a general consensus that the computer laboratories were few hence priority was given to computer related lesson.

The research question on the status of integration of ICT in teaching and learning engineering program found out that the CAD was available in laboratories designated for drawing and design. The finding also revealed that the trainers spent limited number of hours on the use of computer in teaching and learning an indication of low integration of ICT integration for teaching and learning among the engineering trainers.

The results also revealed a low percentage among trainers that use the software. AutoCAD registered 38\%, Presentation software $45 \%$ and Simulation software $17 \%$. $57 \%$ of the trainers used computers during the lesson for not more than 4 hours in a week. In general, the status of integration of ICT in teaching and learning in National Polytechnic from the data analyzed is low despite $64 \%$ of the trainers reporting that they are proficient in using computer.

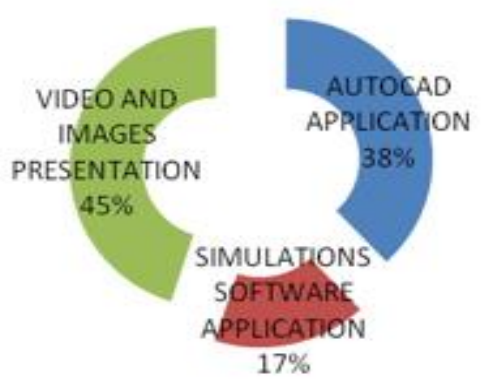

Fig. 2. The competency of trainers to use computer application soft wares.

\section{Findings on Observation Schedule}

On the availability of ICT infrastructure to facilitate integration of ICT in teaching and learning, the study results showed $56 \%$ (10) of the lesson observed were carried out in the computer laboratories where ICT resources such as computer, storage devices, and smart-boards could be accessed. During the observation, it was noted that lecture rooms where theory lessons were carried out were not ICT compliance since power sockets were inadequate, lacked projector screen and not properly secured to install ICT facilities. The numbers of projectors available were inadequate to meet the teaching and learning needs of the trainers and trainees as well. Where the overhead projector were available lacked policies that guide how the resource can be shared among the various entities.

\section{CONCLUSIONS AND RECOMMENDATIONS}

The 21 st century has been described as computer era and what is prominence is the application of information technology for ease of works and enhancement of skill transfer in the era of knowledge economy. It is of principle importance therefore that ICT is integrated in education and training, to accommodate the current and future technological innovations.

Integrating technology in teaching and learning has been proven to be complex and slow due to several factors including inadequate ICT infrastructure, non-proficiency in technology to be able simulate or animate processes, and limited capacity to network and share virtual or remote laboratories for knowledge and skill delivery. The emerging technological skills have outpaced the conventional techniques of skill transfer. The adoption of ICT integration for TL is slow and institutions have not taken advantage of the technology to speed up the acquisition of technological skills.

The institutions selected for this study were conducting engineering training programs with little emphasis towards adoption of ICT for teaching and learning. Engineering skills were being taught using the traditional pedagogy and elearning was not being employed to address the skill gap persisting as a result of emerging technology outpacing the conventional transfer of technical knowledge. E-learning is still in very early stage of adoption for teaching and learning engineering practice.

The globe in modern times is technology flooded and engineering courses must foster practical skills that rejoin timely needs of the industry market, and ICT enabled teaching through virtual /remote laboratories is the 
outstanding methodology to set aside TVET graduates from industry skill miss match.

The study concluded that span and intensity of integrating ICT in engineering training is complex and slow recommending for critical analysis of the known factors associated with acceleration of technology adoption to TL with special focus on the equipment and techniques of using virtual laboratories. This can help the implementers to frame ICT and e-learning policy for engineering training in the light of varied global development. In this study literature review revealed that varied e-learning tools, ICT, supplement teaching in electronics engineering classrooms and laboratories and further to that the trainers trusted that the use of learning tools such as simulations, animations, and virtualized demonstrations in laboratories were more productive than conventional classroom teaching.

\section{REFERENCES}

[1] Albirini, A. (2006). Teachers' attitudes toward information and communication technologies: The case of Syrian EFL teachers. Computers \& Education, 47(4), 373-398.

[2] Banday M. T., Ahmed Musavir \& Jan Tarq,R (2013) Applications of E-learnin in Engineering education: Acase study. Procedia-Social Behavioural Science $123 \quad$ (2014) 406-413, Elsevier. www.sciencedirect.com.

[3] Gomes, L and García-Zubia, J. (2007) "Advances on remote laboratories and eLearning experiences". Bilbao, Universidad de Deusto.

[4] Zhao, Y. \& Frank, K. A. (2003). Factors Affecting Technology Uses in Schools: An Ecological Perspective. American Educational Research Journal, 40 (4), 807-840.

[5] Abdellah, G. \& Taher, S (2007). Recent development in Egyptian Engineering Education thr competitive projects, Egyptian Government report, Egypt.

[6] Peterson, G.D. and Feisel, L.D. (2002) ' e-Learning: The Challenge for Engineering Education', ECI Conference on e-Technologies in Engineering Education: Learning Outcomes Providing Future Possibilities, Davos, Switzerland.

[7] UNESCO (2000) The Right Education: Towards education for all throughout life. 7, Place DeFontenoy, 75352 PARIS, France, published by UNESCO Publishers.
[8] Bryan, J. A., \& Slough S.W (2009) Converging Lens Simulations Design and Image Predictions.

[9] Alessi, S.M., \& Trollip, S. R. (Eds.) (1991). Computer-based instruction: Methods and Development (2nd ed.), Prentice Hall, ISBN 978-0131685925, Englewood Cliffs, NJ.

[10] Banerji, A., \& Bhandari, R. (1996). Virtual laboratory in engineering training and education. Proceedings of the Workshop on Simulationbased Training, PRICAI96, Cairns, Australia, 23-30.

[11] Baily, C., \& Finkelstein, N.D. (2009). Development of quantum perspectives in modern physics, Physical Review Special Topics Physics Education Research, Vol. 5, pp. 010106, ISSN 1554-9178.

[12] Anderson, E. (2001). Incorporating laboratory simulations into nonlaboratory courses. Proceedings of the ICEE, Oslo, Norway.

[13] Jensen, C.G., \& Raisor, E.M. (2000). Terminal served interactive distance learning laboratories.

[14] Higuchi, H. (2000). Multi-level, interactive web-based simulations to teach fluid mechanics at middle school to college levels. Proceedings of the ICEE, Taipei, Taiwan.

[15] Smaill, C., (2006). "The Implementation and Evaluation of OASIS, a Web-Based Learning and Assessment Tool in Electrical Engineering," 36 th.

[16] Zhai, G., Wang, Y., Liu, L., (2012). "Design of Electrical Online Laboratory and E-learning," International Conference on Future Computer Supported Education, 2 (2012), pp. 325-330.

[17] Banday, M.T., (2012). "E-Learning in the Web 2.0 World: A Case Study," IEEE International conference on Engineering Education: Innovative Practices and Future Trends (AICERA 201, Kerela, India July 19 to $21,2012$.

[18] Onwuegbuzie, A.J \& Leech, N.L (2005): The Qualitative Report, Volume 11 Number 3 pp. 474-498.

[19] Greene,Jennifer ,(2007).Toward a Methodology of Mixed Methods Social Inquiry University of IIIinois, Urbana-Champaign.

[20] Orodho, A and Kombo, D. (2002) Research Methods.Nairobi: Kenyatta University, Institute of open learning.

[21] Babette Moeller \& Tim Reitzes (2011). Education Development Centre, Inc. (EDC). Integrating Technology with Student-Centred Learning. Quincy, MA: Nellie Mae Education Foundation. The Nellie Mae Education Foundation 1250 Hancock Street, Suite 205N, Quincy, MA 02169.

[22] Cavas, B., Cavas, P., Karaoglan, B., \& Kisla, T. (2009). A study on science teachers' attitudes toward Information and Communication Technologies in Education. The Turkish Online Journal of Educational Technology - TOJET, 8(2), 20-32.

[23] Agyei, D. D \& Voogt, J. M. (2011). Exploring the potential of the will, skill, and tool model in Ghana: Predicting prospective and practicing teachers' use of technology. Computer \& Education, 56 (1), 91-100. 